\title{
Looking for the "Little Things": A Multi-Disciplinary Approach to Medicines Monitoring for Older People Using the ADRe Resource
}

\author{
David Hughes ${ }^{1}$, Meirion Jordan ${ }^{2}$, Patricia A. Logan ${ }^{3}$, Alan Willson ${ }^{1}$, Sherrill Snelgrove ${ }^{1}$, \\ Melanie Storey ${ }^{1}$, Mojtaba Vaismoradi ${ }^{4}$ (D) and Sue Jordan 1 * (D) \\ 1 Faculty of Health and Life Sciences, Swansea University, Swansea SA2 8PP, UK; \\ d.hughes@swansea.ac.uk (D.H.); a.r.willson@swansea.ac.uk (A.W.); s.r.snelgrove@swansea.ac.uk (S.S.); \\ m.storey@swansea.ac.uk (M.S.) \\ 2 Independent Researcher, Swansea SA9 2GA, UK; meirion.jordan@googlemail.com \\ 3 Faculty of Science, Charles Sturt University, Bathurst 2795, Australia; plogan@csu.edu.au \\ 4 Faculty of Nursing and Health Sciences, Nord University, 8049 Bodø, Norway; mojtaba.vaismoradi@nord.no \\ * Correspondence: s.e.jordan@swansea.ac.uk; Tel.: +44-(0)1792-518541
}

Received: 25 September 2020; Accepted: 15 October 2020; Published: 19 October 2020

\begin{abstract}
Advances in medicines have increased the effectiveness of treatments and the social and cultural authority of doctors. However, as prescribing has become the dominant modality of treatment, the "pharmaceuticalization" of medical practice has often resulted in treatment "at a distance", with doctors having limited contact with patients. Older and poorer people, who are socially distanced from medical prescribers, suffer more adverse drug reactions (ADRs) than the general population. A team approach to checking patients systematically for ADRs, as detailed in manufacturers' literature, can minimise medication errors, but regular review is rare. This paper explains the benefits of medicines monitoring to protect older patients from iatrogenic harm, such as over-sedation, falls, or drug-induced Parkinsonism. We show how multidisciplinary initiatives to optimise prescribing can be supported by using a recognised resource-the adverse drug reaction profile (ADRe). The profile identifies and documents patients' signs and symptoms of putative ADRs. Better monitoring allows professionals to adjust prescribing and respond to identified problems with agility. Implementation of systematic monitoring will require changes to the regulatory regime and better inter-professional cooperation. Providing carers, nurses and pharmacists with a structured system to monitor patients would democratise relevant medical knowledge and help address ageism and the socio-economic health divide.
\end{abstract}

Keywords: adverse drug reactions; patient safety; nursing; medicine management; long-term care; community care; older people care

\section{Introduction}

The benefits of improved medicines developed over the past century [1,2] have been eroded by an increasing incidence of iatrogenic disease arising with the unwanted effects of prescribed drugs $[3,4]$. The European Medicines Agency [5] defines an adverse drug reaction (ADR) as a "noxious and unintended" reaction to a medicinal product. This includes ADRs that arise from both use of a medicinal product within the terms of the marketing authorisation, and use outside the terms of the marketing authorisation, including overdose, off-label use, misuse, abuse and medication errors, as well as occupational exposure [5] (page 6).

ADRs are amongst the most common forms of iatrogenic harms, disproportionately affecting the elderly and the poor and consequently presenting a serious challenge for contemporary healthcare 
systems. This challenge persists despite numerous regulatory and policy initiatives to improve quality of care, due in part to systemic power imbalances between prescribers, patients and non-prescribing healthcare professionals.

Our intervention, the adverse drug reaction profile (ADRe), allows care home staff periodically to record the signs and symptoms of adverse effects of commonly prescribed medicines by completing a paper instrument-a kind of carer administered checklist. It is structured so as to allow detection of common ADRs and provides nurses and other non-prescribers with information to link signs and symptoms on the checklist to prescription medicines. This offers personalised information and evidence that they can bring to the attention of prescribers so as to facilitate improved medicines management [6,7]. We named our profile after the Welsh language word "adre" means "homeward", and implying a return to a place of safety where one can enjoy health and wellbeing. ADRe provides a systematic means of improving drug safety in primary care, while also encouraging new forms of multidisciplinary working that will help to reduce the "care gap" [8] that affects so many older care home residents.

\section{Prescribing as an Expression of Professional Power}

Over- and under-prescribing, and the ADR problem, need to be seen in the wider context of long-term changes in the practice of medicine. Recent decades have seen the increasing "pharmaceuticalization" of medical practice [9-11], whereby the dominant modality of treatment is the prescribing of often powerful medicines. Williams and colleagues (p. 711, [10]) define pharmaceuticalization as "the translation or transformation of human conditions, capabilities and capacities into opportunities for pharmaceutical intervention". Over time, a growing range of human problems are seen as being amenable to medical treatment [12], which increasingly centres on pharmaceutical products, including medicines that control behaviour. Pharmaceuticalization typically leads to a form of "treatment at a distance", a mode of physician engagement with patients where an initial contact leads to an extended course of treatment, the ongoing effects of which are either monitored by patients themselves or by other carers, and where further contact with the doctor is at best episodic. We have argued previously that despite modern efforts to move towards "patient-centred medicine", medical professionals often remain socially distant from certain sections of the population, especially older patients in long-term care facilities [13]. The combination of social distance between doctors and older patients, and treatment centring on drugs prescribed without regular patient contact, increases the risks of medication errors and undetected ADRs. Past studies have found that medical care in nursing homes remains suboptimal; in particular, the inappropriate use of psychotropic medication and shortcomings in pain management remain key concerns in the care of older adults [14-16]. An effective medical monopoly on prescribing dis-incentivises others in the care team from undertaking the work of tracking adverse side effects. These ongoing risks are compounded by the "sick role" status and unintentional "othering" of patients [17], whereby patients risk being defined by their diagnoses and prescriptions and then confined to these powerless states by inadequate medicines management.

Given that the potential harms of prescribed medicines have been consistently underestimated, there is an urgent need for effective medicines management in the care of older adults [18,19]. One study found ADRs affected 7.8\% of primary care patients [20], and in more vulnerable groups, this rises significantly. ADRs have been found to affect $4.8-37 \%$ of people with cognitive impairment [21] and $11.0 \%$ of hospitalised patients [22]. Drug-induced signs and symptoms are difficult to distinguish from underlying disease conditions, often leading to further prescriptions and increasing the risk of drug interactions $[23,24]$. Prescribing depends almost exclusively on the actions of medical professionals, but systematic monitoring to check for ADRs rarely occurs [25-28], and there is no generally-accepted tool for safeguarding patients from under- or over-prescribing [29]. 


\section{ADRs in Older Adults: Systems Failure or Systemic Challenge}

With prescribing taking place within the political context of a medical monopoly, it is concerning that ADRs remain a serious source of harm. Adverse effects of medical treatment (by no means all ADRs) were the underlying cause of an estimated 123,603 deaths in the USA between 1990 and 2016 [30]. Approximately $6 \%$ of patients are harmed by care processes, half of which are preventable [31]. Over recent decades, ADRs have been responsible for $5-8 \%$ of unplanned UK hospital admissions [32,33], rising to around 10\% amongst older adults [34]. One English study [35] estimated that the cost of avoidable ADRs was at least $£ 98.5$ million per annum, and probably significantly higher, while another put the figure at between a billion and 2.5 billion pounds [36]. Moreover, the impacts of ADRs are often more prevalent among older adults, with all-cause mortality highest amongst those prescribed mental health medicines [4].

Both ADRs and failure to prescribe necessary medicines increase mortality and hospital admissions, and this underlines the central importance of prescribing for contemporary health care [37]. Population ageing and the increasing volume of drugs prescribed will worsen these problems. Doses for mental health medicines in care homes [38] and primary care [18] are often excessive, and research suggests that over half of care home residents may be affected [39]. ADRs from these sources can be life-threatening but are often ignored or mistaken for symptoms of ageing or underlying disease [6]. There remains strong evidence that most ADRs are preventable $[25,37,38]$. Additional enhanced monitoring is one component of the change needed to address this challenge [37,38,40-44]. We need comprehensive, systematic and multi-professional approaches to improve patient safety [29,45]. It is crucial to involve the wider care team rather than rely only on monitoring by prescribers.

\section{ADRe and Systematic Medicines Management as a Route to Effective Change}

The urgency of this problem is underlined by research that identifies medicine-related harms as the main source of unsafe primary care in England and Wales [46]. Nonetheless, the majority of ADRs and other medicine-related harms arise from poor monitoring rather than errors in prescribing [32,33,40-43], being primarily dose-related [44]. The situation can be greatly improved by enhanced monitoring and reporting $[18,19,47]$. ADRe was developed from earlier research on nurse-led medication checking, originally in relation to mental health medicines prescribed for clients of community mental health teams [48-50].

\section{How Is ADRe Different?}

ADRe represents a unique approach to assembling patient information, checking and optimising prescribing and preventing drug-related harm and hospital admissions. Staff use the paper instrument at intervals of approximately three months or before scheduled appointments with doctors or pharmacists to collect systematic information for each patient, including on signs and symptoms of known adverse effects of commonly prescribed medicines. The profile is designed to detect "undesirable" side effects based on manufacturers' summaries of product characteristics (SmPCs). The guide provided with ADRe suggests possible causes for each sign or symptom. Information collected is then shared with pharmacists and prescribers considering repeat prescriptions or reviewing medicines administration record (MAR) charts. ADRe thus represents a multidisciplinary intervention to complement wider regulatory initiatives seeking to improve medicines management and reduce errors. This is illustrated by stakeholders' views (Figure 1). The authors' review of the literature found no alternative comprehensive, systematic patient assessment tool for monitoring prescribed medicines [6,45].

While many interventions aid the selection of appropriate medication, few have demonstrated improvement in patient outcomes [32,34]. ADRe is different-it addresses the "little" things affecting patients, aiming to prevent serious adverse events, for example, by addressing dizziness, balance and poor eyesight before falls happen. The attention to detail that ADRe permits explains the improvement in symptoms such as pain, dyspnoea, sedation, aggression and confusion we found in our 2019 study [6]. 


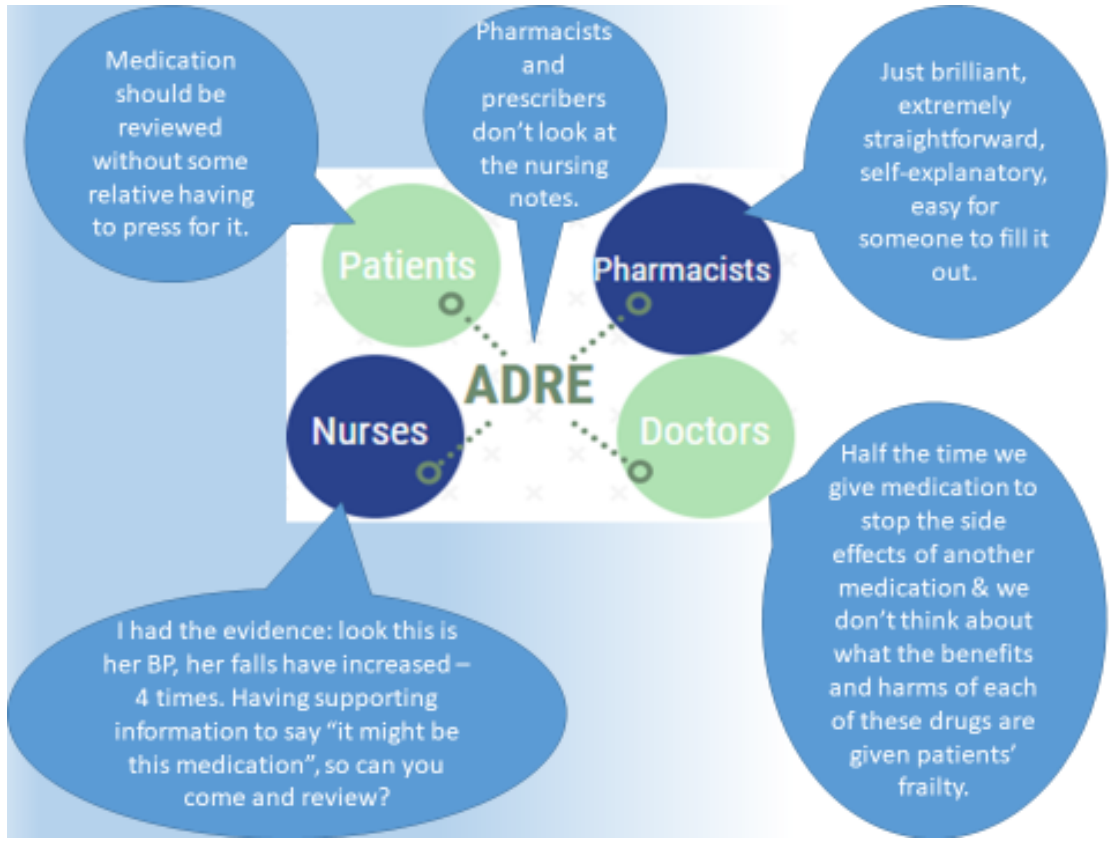

Figure 1. The adverse drug reaction profile (ADRe): some stakeholder opinions. These previously unpublished quotations come from 30 qualitative interviews with service users, care home staff and professionals completed in our 2019 study [6,7]. In brief, we interviewed nurses and residents (or family) from 10 care homes, as well as a range of stakeholders, including pharmacists and prescribing doctors, to identify the barriers and facilitators to using ADRe in real-world settings. The methods are detailed elsewhere [7].

\section{What Does ADRe Entail?}

ADRe focuses on systematic checks for an itemized set of adverse or undesirable effects of patients' mental health medicines. It also asks care staff to take action in case of problems and, crucially, to share that information with pharmacists and prescribers. It formalises and standardises the approach to monitoring patients' prescribed mental health medicines. Problems identified are then considered alongside the prescription record, and the multidisciplinary team reviews possible adverse effects and decides whether prescriptions need to be repeated, discontinued or changed. ADRe allows non-prescribing practitioners to present direct evidence for their concerns to prescribers. In our study of the implementation of ADRe in ten care homes [6,7], several respondents commented on the opportunity for greater engagement that the tool provided (see Figure 1):

"The CPN started a resident on lurasidone and after a week, we noticed her behaviour had escalated: she was restless, constipated, dehydrated, confused, disorientated, far worse than she had been, ( . . ) I made some notes on it [ADRe], to lead me in the right directions, really to go down the right path. (... ) Rather than just, trying to put my opinion across, I had the evidence in front of me, the things to say 'actually, it might be this medication, so can you come and review?' The CPN might have said 'carry on', but she said 'ok, fair enough', and came back and we had a good result. It's useful, definitely useful, but quite complex to work on. She's still quite challenging but we haven't got all these issues, side effects, any more." (Care home lead nurse, N6)

Pharmacists too commented on how the instrument had the potential to change patterns of communication between professionals and care home staff.

"Trying to get hold of the GPs in the first place... We have no direct line of communication with them. Some surgeries are extremely difficult to get hold of to get to the actual receptionist 
to get request a conversation with the GPs. That is a major barrier. When you can get hold of them, they [GPs] are absolutely fine. ( ... ) A person could be absolutely fine when the nurse comes to visit and then for the rest of the day, they could be exhibiting some sort of symptom or side effect. So if the carers were able to use this [ADRe] it would be extremely valuable ( ... ) and if they need help, to come to us rather than the GP." (Retail pharmacist)

ADRe thus functions to address the physical and social distance and difference in power between prescribers and other health care workers, improving communication and improving care. It also augments the role and increases the visibility of pharmacists, who, while having more training in therapeutics than any of the other professions, are often distanced from patients and their symptoms. Figure 2 uses a typical case to illustrate how ADRe identifies problems, which are then addressed. In this instance, prescribers felt that prescriptions should remain until the resident had settled into the care home; however, the risk of falls was addressed by nursing actions. 


\begin{tabular}{|c|c|c|c|c|}
\hline $\begin{array}{l}\text { Problems Noted on } \\
\text { ADRe }\end{array}$ & $\begin{array}{l}\text { ADRe } \\
\text { Assessment }\end{array}$ & $\begin{array}{l}\text { Supporting Information } \\
\text { Related to Falls }\end{array}$ & Medicines Pres & Outcome \\
\hline $\begin{array}{l}\text { Addressing Falls } \\
\text { Man aged > } 85 \text { ( } 3.1 \text { BP } \\
\text { sitting 175/92, standing } \\
\text { 139/71 mmHg. Fell on } \\
\text { standing } 2 \text { weeks } \\
\text { earlier. Taken to } \\
\text { accident department } \\
\text { for sutures. ADRe was } \\
\text { the only record of } \\
\text { postural hypotension. } \\
\text { Problems on ADRe } \\
\text { 1. Wt loss (now } 64 \text { kg) } \\
\text { 2. hand tremor } \\
\text { 3. tongue tremor } \\
\text { 4. feet shuffle } \\
\text { 5.abnormal } \\
\text { movements } \\
\text { 6. posture } \\
\text { 7. gait } \\
\text { 8. balance }\end{array}$ & $\begin{array}{l}\text { Please review } \\
\text { information } \\
\text { on assessing }\end{array}$ & $\begin{array}{l}\text { Recheck BP lying and } \\
\text { standing, review balance, } \\
\text { dizziness, tinnitus and } \\
\text { vision, and seek } \\
\text { medication review. } \\
\text { Check if a B12 injection is } \\
\text { due. } \\
\begin{array}{l}\text { Mental health medicines, } \\
\text { opioids, anti- } \\
\text { hypertensives, beta }\end{array}\end{array}$ & $\begin{array}{l}\text { - } \quad \text { ramipril } 2.5 \mathrm{mg} \text { o.d. } \\
\text { m/r capsules o.d. } \\
\text { zopiclone } 7.5 \mathrm{mg} \\
\text { nocte } \\
\text { bendroflumethiazid } \\
\text { e } 2.5 \mathrm{mg} \text { o.d. } \\
\text { clopidogrel } 75 \mathrm{mg} \\
\text { o.d. } \\
\text { doublebase gel. } \\
\text { When required } \\
\text { finasteride } 5 \mathrm{mg} \\
\text { o.d. } \\
\text { haloperidol } 500 \\
\text { mcg capsules, take } \\
1 \text { mane, } 2 \text { at } 5 \text { pm } \\
\text { paracetamol } 500 \mathrm{mg} \\
1-2 \text { taken } 4 \text { times } \\
\text { day }\end{array}$ & $\begin{array}{l}\text { No further falls. } \\
\text { Falls risk re-assessed by nurses, and care plan changed to } \\
\text { ensure safe mobilisation. } \\
\text { Medicines reviewed, and haloperidol scheduled for } \\
\text { reduction in line with care home policy. } \\
\text { Diet monitored and snacks and intake encouraged. } \\
\text { Pharmacist's comments: } \\
\text { 1. Postural BP drop noted-bendroflumethiazid, } \\
\text { ramipril and tamsulosin, review } \\
\text { 2.Zopiclone and haloperidol also increase falls risk, } \\
\text { review } \\
\text { 3. Extrapyramidal side effects (tremor, etc.)- } \\
\text { haloperidol, review. } \\
\text { Interactions from BNF } \\
\text { 1. Haloperidol and ramipril-enhanced hypotensive } \\
\text { effect } \\
\text { 2. Tamsulosin and zopiclone-enhanced hypotensive } \\
\text { and sedative effect } \\
\text { 3. Bendroflumethiazide and zopiclone-enhanced } \\
\text { hypotensive effect }\end{array}$ \\
\hline
\end{tabular}

Figure 2. Cont. 


\begin{tabular}{|c|c|c|c|}
\hline $\begin{array}{l}\text { 9. behaviour } \\
\text { 10. irritability } \\
\text { 11. agitation } \\
\text { 12.restless (wandering) } \\
\text { 13. confusion } \\
\text { 14. mood fluctuations } \\
\text { 15. falls } \\
\text { 16. incontinence } \\
\text { 17. diet lacks vitamin D } \\
\text { 18. vision } \\
\text { 19. medicines missed }\end{array}$ & $\begin{array}{l}\text { Falls, } \\
\text { consider }\end{array}$ & 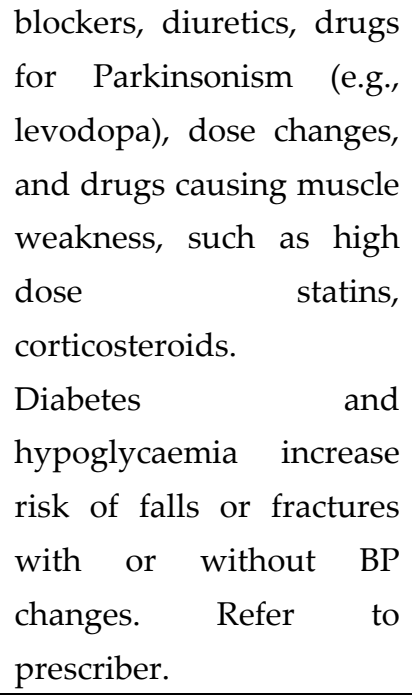 & $\begin{array}{l}\text { 4. Ramipril and zopiclone-enhanced hypotensive effect } \\
\text { 5. Haloperidol and zopiclone-increased sedative effect } \\
\text { 6. Tamsulosin and haloperidol-enhanced hypotensive } \\
\text { effect } \\
\text { 7. Ramipril and tamsulosin-enhanced hypotensive } \\
\text { effect } \\
\text { 8. Potentially serious, ramipril and } \\
\text { bendroflumethiazide-enhanced hypotensive effect } \\
\text { 9. Potentially serious, tamsulosin and } \\
\text { bendroflumethiazide-enhanced hypotensive effect. }\end{array}$ \\
\hline
\end{tabular}

Figure 2. ADRe in action: preventing falls. ADRe: the adverse drug reaction profile, N.B. Medicines relevant to the resident are emboldened in the supporting information, $\mathrm{BP}=$ blood pressure, o.d. = omni die (every day). 


\section{ADRe in the Context of Regulatory and Policy Interventions}

ADRs are often unrecognised [13], but as we have seen they have very significant impacts in terms of increased morbidity, premature mortality and financial cost to the UK National Health Service (NHS). These impacts are sufficiently weighty and widespread that they require intervention at the policy level. It is clear that there is a pressing need for policy intervention to address the problem of ADRs in older adults $[6,13]$.

Policy intervention is important to encourage care homes to get past the common initial perception that using a resource such as ADRe imposes a work burden that they cannot afford. Our study found that familiarity reduces the time taken to administer ADRe to around $10 \mathrm{~min}$ per patient each month or each quarter. Once familiarity is gained, routine use becomes relatively easy. The problem is that a push is needed to persuade care homes to take the first step. Our experience in Wales suggests that research evidence of health gain and even endorsement by authoritative bodies have, to date, been insufficient to ensure rollout beyond the most innovative care homes. ADRe has been endorsed by the Royal Pharmaceutical Society and recommended as best practice by the All Wales Medicines Strategy Group, but this has yet to impact on policy makers and practice. Disappointingly, the COVID-19 pandemic did not lead to uptake of a resource to monitor changes in oxygen saturation, temperature, cough (and respiratory symptoms) or changes in appetite and taste, where ADRe would prove very beneficial to longer term patients.

In our view, what might make a difference is for the statutory inspection bodies to encourage care homes to use a formal medicines monitoring tool. While Care Inspectorate Wales has a remit to monitor medicines administration in care homes, it takes the view that it has no power under existing government guidance to require homes to use particular monitoring tools. It does use an audit questionnaire, developed in cooperation with the chief pharmacist, to assess the general approach taken, but this is a blunt instrument for addressing the magnitude and complexity of the ADR problem. Including a question that asks whether homes utilise an evidence-based resource and regarding this as an indicator of good practice, would incentivize more homes to safeguard against iatrogenic harm. In the longer term, it may be possible to go a step further and change guidance to require use of a formal medicines monitoring tool in all registered care homes.

Changing practice will depend on mobilizing support for ADRe through persuasion within the key influence networks and grappling with the professional politics of the health service tribes. The challenge is to convince policy makers that a person-centred, clinically- and cost-effective resource, such as ADRe, deserves support. If policy-makers push inspection bodies, and in due course the local government commissioners (who fund much care on a means-tested basis), to demand robust medicines monitoring in care homes, as an indicator of safe or good practice, then better control of ADRs becomes realistic. What gets documented gets done. We have consistently found that less than half of potential problems were documented in patients' notes until ADRe was introduced [29]. Only some $5 \%$ of serious ADRs are reported via voluntary systems, such as the UK's "yellow cards" [51], and reports are vulnerable to respondent and notoriety biases [52,53]. Addressing these systemic failings will require government to show the political will to go beyond lip service to better medicines management $[54,55]$ and take concrete steps to make it happen.

\section{A Professional Blind Spot: Out of Sight, Out of Mind}

Identifying the unintended consequences of prescribing, particularly amongst vulnerable groups, is a challenge for those regulating the marketing of medicines; however, regulators, like individual prescribers, depend on the recording of patients' responses to medicines [56]. Large electronic databases hold information on drug utilisation, mortality, medical diagnoses and reasons for hospital admission, but outcomes important to patients, such as continence, pain and xerostomia, are rarely recorded [29].

This system-level blind spot is echoed at the level of individual practitioners: not all practitioners have memorised all the possible adverse effects of the medicines they prescribe, dispense and administer. ADRe tries to democratise that knowledge in its supporting information, ensuring carers, nurses and 
pharmacists have a voice in key clinical decisions concerning medicines management and alerting them to possible irregularities or even errors in prescribing. However, in the context of professional monopoly, sharing knowledge with other professions is not always welcomed [8].

Recognizing ADRs often depends on close engagement with patients over time, requiring healthcare professionals to observe and understand behaviour (e.g., posture and movement disorders, responses to pain) in ways that highlight social and cultural differences between patient and professional. Identifying a causal connection between an ADR and a behavioural sign is a complex, highly contingent social process, involving multi-faceted clinical and common-sense judgements. ADRe has a crucial role to play in addressing these challenges, creating an appropriate "index of suspicion" by equipping practitioners with the necessary supporting information.

Social and geographical distances between prescribers and patients pervade the contemporary UK healthcare system. Social, cultural and ethnic differences create barriers in communication and prescribers' understanding of the impact of medicines on the physical and mental wellbeing of patients, sometimes leading to stereotyping and reducing the role of the patient to "other" [57-59]. Studies suggest that age is a factor in the way doctors interact with patients, and that older patients may be disadvantaged [60-62]. Such a profound and systemic challenge creates, as its logical consequence, distances between the prescribing or de-prescribing event and clinical outcomes, removing ADRs from the medical gaze. These problems increase with distance, intensifying health inequalities and resulting in ever-sharper divides in the quality of care between socially and geographically distinct populations.

\section{ADRs and the Health Divide}

UK primary care is characterised by the inverse care law [63], whereby resources are diverted away from areas of social deprivation and the greatest medical need. General practitioners (GPs) in the most deprived areas are responsible for more patients and are under greater pressures and risk of burnout [64] Socio-economic deprivation increases the use of prescription medicines and the associated risks of adverse side effects. For example, prescription of antipsychotics [65] and polypharmacy ( $\geq 10$ medicines) [66] are concentrated in more deprived socio-economic groups, leading to concerns that ADRs are contributing to health inequalities [67]. The gap between rich and poor in life expectancy and healthy life expectancy is increasing, with a difference of up to 9.5 years of life expectancy between the least and most deprived areas of England [68]. The increasing impact of deprivation highlights the need for interventions that can help mitigate the social distance between doctors and certain patient groups. Accordingly, a resource like ADRe, which can be used by care assistants, is an important strategy to democratise knowledge and improve care for the most disadvantaged.

The increased demand for healthcare has been addressed by role expansion of non-medical healthcare professionals, including nurses [69]. A higher proportion of prescription items are initiated by nurses in areas of socio-economic deprivation and where the number of GPs per 100,000 population falls below 60 [70]. The limited dissemination of medical knowledge outside the body of medical professionals here makes a crucial impact; nurses, even when qualified to prescribe, do not have the same training and background knowledge of pharmacology as doctors, and substitution confined to disadvantaged areas has been a concern. Practice guidelines and systematic approaches may support practitioners and enhance care in relatively unfamiliar professional territory [71], and ADRe offers such a strategy for adults prescribed commonly-used medicines in primary care.

\section{Conclusions}

ADRs present the current UK healthcare system with stark challenges. The social imbalances between prescribers, patients, and non-prescribing healthcare professionals mean that the physical and mental wellbeing of patients is often neglected and hampers a truly multidisciplinary response to ADRs. Not all patients are served equally by this system, with medical resources more thinly spread across older and poorer sections of the population. Moreover, the knowledge that would allow non-medical 
healthcare professionals to meet the shortfall is not adequately disseminated, leaving nurses and other carers "out of the loop".

ADRe offers a cost-effective step towards meaningful systemic change. It comprehensively documents the multivalent problems patients may be experiencing, giving nurses a knowledge framework that enables them to present evidence to prescribers. Beyond this, it may offer a means of addressing the iatrogenic harms and waste identified by researchers [72]. ADRe offers a real chance of bridging the divides inherent in the present healthcare system and the underlying inequalities that create them.

Author Contributions: All authors have met all the following criteria: substantial contributions to conception and design, acquisition of data, or analysis and interpretation of data, drafting the article or revising it critically for important intellectual content. All authors have read and agreed to the published version of the manuscript.

Funding: This paper received no external funding. The research cited was funded by Abertawe Bro Morgannwg (now Swansea Bay) University Health Board, and sponsored by Swansea University.

Acknowledgments: Part of this paper is based on a presentation at the Measuring impact of Pharmacovigilance Information Day on 14 November 2017 at the EMA, Canary Ward, London organised by DIA (develop, innovate advance) for industry delegates: Jordan S., Outline of a process to identify intended (and unintended) public health outcomes of regulatory decisions.

Conflicts of Interest: The authors declare no conflict of interest.

\section{References}

1. Sampson, C.; O'Neill, P.; Lorgelly, P. The Impact of New Medicines in the NHS: 70 Years of Innovation. OHE Consulting Report. 2018. Available online: https://www.ohe.org/publications/impact-new-medicinesnhs-70-years-innovation (accessed on 25 September 2020).

2. Weinshilboum, R.M. The therapeutic revolution. Clin. Pharm. Ther. 1987, 42, 481-484. [CrossRef]

3. D'Arcy, P.F. Iatrogenic disease: A hazard of multiple drug therapy. R. Soc. Health J. 1976, 96, 277-283. [PubMed]

4. Stolley, J.M.; Buckwalter, K.C.; Fjordbak, B.; Bush, S. Iatrogenesis in the elderly. Drug-related problems. J. Gerontol. Nurs. 1991, 17, 12-17. [CrossRef] [PubMed]

5. European Medicines Agency (EMA). Guideline on Good Pharmacovigilance (GVP)-Module VI-Collection, Management and Submission of Reports of Suspected Adverse Reactions to Medicinal Products (Rev 2). 2017, p. 6. Available online: http://www.ema.europa.eu/docs/en_GB/document_library/Regulatory_and_ procedural_guideline/2017/08/WC500232767.pdf (accessed on 25 September 2020).

6. Jordan, S.; Banner, T.; Gabe-Walters, M.; Mikhail, J.M.; Panes, G.; Round, J.; Snelgrove, S.; Storey, M.; Hughes, D. Nurse-led medicines' monitoring in care homes, implementing the Adverse Drug Reaction (ADRe) Profile improvement initiative for mental health medicines: An observational and interview study. PLoS ONE 2019, 14, e0220885. [CrossRef] [PubMed]

7. Jordan, S.; Banner, T.; Gabe-Walters, M.; Mikhail, J.; Round, J.; Snelgrove, S.; Storey, M.; Wilson, D.W.; Hughes, D. Nurse-led medicines' monitoring in care homes study protocol: A process evaluation of the impact and sustainability of the adverse drug reaction (ADRe) profile for mental health medicines. BMJ Open 2018, 8, e023377. [CrossRef] [PubMed]

8. Jordan, S.; Hughes, D. Bioscience knowledge and the health professions: Has professional monopoly created a care gap? Soc. Sci. Health 1996, 2, 80-92.

9. Abrahams, J. Pharmaceuticalization of society in context: Theoretical, empirical and health dimensions. Sociology 2010, 44, 603-622. [CrossRef]

10. Williams, S.J.; Martin, P.; Gabe, J. The pharmaceuticalisation of society? A framework for analysis. Sociol. Health Illn. 2011, 33, 710-725. [CrossRef]

11. Bell, S.E.; Figert, A.E. Medicalization and pharmaceuticalization at the intersections: Looking backward, sideways and forward. Soc. Sci. Med. 2012, 75, 775-783. [CrossRef]

12. Conrad, P. The Medicalization of Society; John Hopkins University Press: Baltimore, MD, USA, 2007.

13. Jordan, S.; Logan, P.A.; Panes, G.; Vaismoradi, M.; Hughes, D. Adverse drug reactions, power, harm reduction, regulation and the ADRe profiles. Pharmacy 2018, 6, 102. [CrossRef] 
14. Banerjee, S. The Use of Antipsychotic Medication for People with Dementia: Time for Action. A Report for the Minister of State for Care Services. An Independent Report Commissioned for the Department of Health. 2009. Available online: https://www.jcpmh.info/wp-content/uploads/time-for-action.pdf (accessed on 25 September 2020).

15. Sherlaw-Johnson, C.; Crump, H.; Curry, N.; Paddison, C.; Meaker, R. Transforming Health Care in Nursing Homes: An Evaluation of a Dedicated Primary Care Service in Outer East London. 2018. Available online: https://www.nuffieldtrust.org.uk/research/transforming-health-care-in-nursing-homes-anevaluation-of-a-dedicated-primary-care-service-in-outer-east-london (accessed on 25 September 2020).

16. Szczepura, A.; Clay, D.; Nelson, S.; Wild, D.; Spilsbury, K. Improving Care in Residential Care Homes: A Literature Review. 2008. Available online: https://www.jrf.org.uk/report/improving-care-residential-carehomes-literature-review (accessed on 25 September 2020).

17. Roberts, M.L.A.; Schiavenato, M. Othering in the nursing context: A concept analysis. Nurs. Open 2017, 4, 174-181. [CrossRef] [PubMed]

18. Hoffmann, T.C.; Del Mar, C. Patients' expectations of the benefits and harms of treatments, screening, and tests: A systematic review. JAMA Intern. Med. 2015, 175, 274-286. [CrossRef] [PubMed]

19. Hoffmann, T.C.; Del Mar, C. Clinicians' expectations of the benefits and harms of treatments, screening, and tests: A systematic review. JAMA Intern. Med. 2017, 177, 407-419. [CrossRef]

20. Hakkarainen, K.M.; Andersson Sundell, K.; Petzold, M.; Hägg, S. Prevalence and perceived preventability of self-reported adverse drug events—A population-based survey of 7099 adults. PLoS ONE 2013, 8, e73166. [CrossRef]

21. Kanagaratnam, L.; Dramé, M.; Trenque, T.; Oubaya, N.; Nazeyrollas, P.; Novella, J.L.; Jolly, D.; Mahmoudi, R. Adverse drug reactions in elderly patients with cognitive disorders: A systematic review. Maturitas 2016, 85, 56-63. [CrossRef] [PubMed]

22. Alhawassi, T.M.; Krass, I.; Bajorek, B.V.; Pont, L.G. A systematic review of the prevalence and risk factors for adverse drug reactions in the elderly in the acute care setting. Clin. Interv. Aging 2014, 9, 2079-2086. [CrossRef]

23. Piggott, K.L.; Mehta, N.; Wong, C.L.; Rochon, P.A. Using a clinical process map to identify prescribing cascades in your patient. BMJ 2020,368, m261. [CrossRef]

24. Tangiisuran, B.; Wright, J.; Van der Cammen, T.; Rajkumar, C. Adverse drug reactions in elderly: Challenges in identification and improving preventative strategies. Age Ageing 2009, 38, 358-359. [CrossRef]

25. Bouvy, J.C.; De Bruin, M.L.; Koopmanschap, M.A. Epidemiology of adverse drug reactions in Europe: A review of recent observational studies. Drug Saf. 2015, 38, 437-453. [CrossRef]

26. Deilkås, E.T.; Risberg, M.B.; Haugen, M.; Lindstrøm, J.C.; Nylén, U.; Rutberg, H.; Michael, S. Exploring similarities and differences in hospital adverse event rates between Norway and Sweden using Global Trigger Tool. BMJ Open 2017, 7, e012492. [CrossRef]

27. Vaismoradi, M.; Vizcaya Moreno, F.; Sletvold, H.; Jordan, S. PRN Medicines' management for psychotropic medicines in long-term care settings: A systematic review. Pharmacy 2019, 7, 157. [CrossRef] [PubMed]

28. Vaismoradi, M.; Amaniyan, S.; Jordan, S. Patient safety and pro re nata prescription and administration: A systematic review. Pharmacy 2018, 6, 95. [CrossRef] [PubMed]

29. Jordan, S.; Gabe-Walters, M.E.; Watkins, A.; Humphreys, I.; Newson, L.; Snelgrove, S.; Dennis, M.S. Nurse-led medicines' monitoring for patients with dementia in care homes: A pragmatic cohort stepped wedge cluster randomised trial. PLoS ONE 2015, 10, e0140203. [CrossRef] [PubMed]

30. Sunshine, J.E.; Meo, N.; Kassebaum, N.J.; Collison, M.L.; Mokdad, A.H.; Naghavi, M. Association of adverse effects of medical treatment with mortality in the United States: A secondary analysis of the global burden of diseases, injuries, and risk factors study. JAMA Netw. Open 2019, 2, e187041. [CrossRef]

31. Panagioti, M.; Khan, K.; Keers, R.N.; Abuzour, A.; Phipps, D.; Kontopantelis, E.; Bower, P.; Campbell, S.; Haneef, R.; Avery, A.J.; et al. Prevalence, severity, and nature of preventable patient harm across medical care settings: Systematic review and meta-analysis. BMJ 2019, 366, 14185. [CrossRef]

32. NICE Medicines and Prescribing Centre. Medicines Optimisation: The Safe and Effective Use of Medicines to Enable the Best Possible Outcomes; NICE Guideline 5; NICE. 2015. Available online: https://www.nice.org.uk/guidance/ng5/resources/medicines-optimisation-the-safe-and-effectiveuse-of-medicines-to-enable-the-best-possible-outcomes-pdf-51041805253 (accessed on 25 September 2020).

33. Pirmohamed, M.; James, S.; Meakin, S.; Green, C.; Scott, A.K.; Walley, T.J.; Farrar, K.; Park, B.K.; Breckenridge, A.M. Adverse drug reactions as cause of admission to hospital: Prospective analysis of 18820 patients. BMJ 2004, 329, 15-19. [CrossRef] 
34. Kongkaew, C.; Noyce, P.R.; Ashcroft, D.M. Hospital admissions associated with adverse drug reactions: A systematic review of prospective observational studies. Ann. Pharm. 2008, 42, 1017-1025. [CrossRef]

35. Elliott, R.A.; Camacho, E.; Jankovic, D.; Sculpher, M.J.; Faria, R. Economic analysis of the prevalence and clinical and economic burden of medication error in England. BMJ Qual. Saf. 2020. [CrossRef]

36. Frontier Economics. Exploring the Costs of Unsafe Care in the NHS: A Report Prepared for the Department of Health; Frontier Economics: London, UK, 2014. Available online: https://www.frontier-economics.com/media/2459/ exploring-the-costs-of-unsafe-care-in-the-nhs-frontier-report-2-2-2-2.pdf (accessed on 25 September 2020).

37. Thomas, R.E.; Nguyen, L.T.; Jackson, D.; Naugler, C. Potentially inappropriate prescribing and potential prescribing omissions in 82,935 older hospitalised adults: Association with hospital readmission and mortality within six months. Geriatrics 2020, 5, 37. [CrossRef]

38. Stewart, R.; Hotopf, M.; Dewey, M.; Ballard, C.; Bisla, J.; Calem, M.; Fahmy, V.; Hockley, J.; Kinley, J.; Pearce, H.; et al. Current prevalence of dementia, depression and behavioural problems in the older adult care home sector: The South East London Care Home Survey. Age Ageing 2014, 43, 562-567. [CrossRef]

39. Sköldunger, A.; Fastbom, J.; Wimo, A.; Fratiglioni, L.; Johnell, K. Impact of inappropriate drug use on hospitalizations, mortality, and costs in older persons and persons with dementia: Findings from the SNAC study. Drugs Aging 2015, 32, 671-678. [CrossRef] [PubMed]

40. Beijer, H.J.; de Blaey, C.J. Hospitalisations caused by adverse drug reactions (ADR): A meta-analysis of observational studies. Pharm World Sci. 2002, 24, 46-54. [CrossRef] [PubMed]

41. Brenner, S.; Detz, A.; López, A.; Horton, C.; Sarkar, U. Signal and noise: Applying a laboratory trigger tool to identify adverse drug events among primary care patients. BMJ Qual. Saf. 2012, 21, 670-675. [CrossRef]

42. Forster, A.J.; Murff, H.J.; Peterson, J.F.; Gandhi, T.K.; Bates, D.W. Adverse drug events occurring following hospital discharge. J. Gen. Intern. Med. 2005, 20, 317-323. [CrossRef]

43. Gurwitz, J.H.; Field, T.S.; Judge, J.; Rochon, P.; Harrold, L.R.; Cadoret, C.; Lee, M.; White, K.; LaPrino, J.; Erramuspe-Mainard, J.; et al. The incidence of adverse drug events in two large academic long-term care facilities. Am. J. Med. 2005, 118, 251-258. [CrossRef]

44. Steinman, M.A.; Handler, S.M.; Gurwitz, J.H.; Schiff, G.D.; Covinsky, K.E. Beyond the prescription: Medication monitoring and adverse drug events in older adults. J. Am. Geriatr. Soc. 2011, 59, 1513-1520. [CrossRef] [PubMed]

45. Jordan, S.; Vaismoradi, M.; Griffiths, P. Adverse Drug Reactions, Nursing and policy: A narrative review. Ann. Nurs. Pract. 2016, 3, 1-7.

46. Cooper, A.; Edwards, A.; Williams, H.; Evans, H.P.; Avery, A.; Hibbert, P.; Makeham, M.; Sheikh, A.; Donaldson, L.J.; Carson-Stevens, A. Sources of unsafe primary care for older adults: A mixed-methods analysis of patient safety incident reports. Age Ageing 2017, 46, 833-839. [CrossRef]

47. Vaismoradi, M.; Vizcaya-Moreno, F.; Jordan, S.; Gåre Kymre, I.; Kangasniemi, M. Disclosing and reporting practice errors by nurses in residential long-term care settings: A systematic review. Sustainability 2020, 12, 2630. [CrossRef]

48. Jordan, S.; Tunnicliffe, C.; Sykes, A. Minimizing side-effects: The clinical impact of nurse-administered 'side-effect' checklists. J. Adv. Nurs. 2002, 37, 155-165. [CrossRef]

49. Gabe, M.E.; Davies, G.A.; Murphy, F.; Davies, M.; Johnstone, L.; Jordan, S. Adverse drug reactions: Treatment burdens and nurse-led medication monitoring. J. Nurs. Manag. 2011, 19, 377-392. [CrossRef]

50. Jones, R.; Moyle, C.; Jordan, S. Nurse-led medicines monitoring: A study examining the effects of the West Wales Adverse Drug Reaction Profile. Nurs. Stand. 2016, 31, 42-53. [CrossRef] [PubMed]

51. Hazell, L.; Shakir, S.A. Under-reporting of adverse drug reactions: A systematic review. Drug Saf. 2006, 29, 385-396. [CrossRef] [PubMed]

52. De Boissieu, P.; Kanagaratnam, L.; Abou Taam, M.; Roux, M.P.; Dramé, M.; Trenque, T. Notoriety bias in a database of spontaneous reports: The example of osteonecrosis of the jaw under bisphosphonate therapy in the French national pharmacovigilance database. Pharm. Drug Saf. 2014, 23, 989-992. [CrossRef] [PubMed]

53. Pariente, A.; Gregoire, F.; Fourrier-Reglat, A.; Haramburu, F.; Moore, N. Impact of safety alerts on measures of disproportionality in spontaneous reporting databases: The notoriety bias. Drug Saf. 2007, 30, 891-898. [CrossRef]

54. Older People's Commissioner for Wales. A Place to Call Home. 2014. Available online: https://www.olderpeoplewales.com/Libraries/Uploads/A_Place_to_Call_Home_-_A_Review_into_ the_Quality_of_Life_and_Care_of_Older_People_living_in_Care_Homes_in_Wales.sflb.ashx (accessed on 25 September 2020). 
55. Older People's Commissioner for Wales. A Place to Call Home: Impact and Analysis. 2018. Available online: http://www.olderpeoplewales.com/Libraries/chrfollowupreport/A_Place_to_Call_Home_ __Impact_Analysis.sflb.ashx (accessed on 25 September 2020).

56. Finnegan, G. HTA Bodies and Regulators Have a Shared Interest in Understanding Patient Experience, Patient Focused Medicines Development. 2020. Available online: https://patientfocusedmedicine. org/hta-bodies-and-regulators-have-a-shared-interest-in-understanding-patient-experiences/ (accessed on 25 September 2020).

57. Jensen, J.D.; King, A.J.; Guntzviller, L.M.; Davis, L.A. Patient-provider communication and low-income adults: Age, race, literacy, and optimism predict communication satisfaction. Patient Educ. Couns 2010, 79, 30-35. [CrossRef] [PubMed]

58. Verlinde, E.; De Laender, N.; De Maesschalck, S.; Deveugele, M.; Willems, S. The social gradient in doctor-patient communication. Int. J. Equity Health 2012, 11, 12. [CrossRef]

59. Willems, S.; De Maesschalck, S.; Deveugele, M.; Derese, A.; De Maeseneer, J. Socio-economic status of the patient and doctor-patient communication: Does it make a difference? Patient Educ. Couns 2005, 56, 139-146. [CrossRef]

60. Beisecker, A.E. Older persons' medical encounters and their outcomes. Res. Aging 1996, 18, 9-31. [CrossRef]

61. Macrae, H. "My opinion is that doctors prefer younger people": Older women, physicians and ageism. Ageing Soc. 2018, 38, 240-266. [CrossRef]

62. Peck, B.M. Age-related differences in doctor-patient interaction and patient satisfaction. Curr. Gerontol. Geriatr. Res. 2011, 2011, 137492. [CrossRef] [PubMed]

63. Tudor Hart, J. The inverse care law. Lancet 1971, 297, 405-412. [CrossRef]

64. Pedersen, A.F; Vedsted, P. Understanding the inverse care law: A register and survey-based study of patient deprivation and burnout in general practice. Int. J. Equity Health 2014, 13, 121. [CrossRef]

65. Marston, L.; Nazareth, I.; Petersen, I.; Walters, K.; Osborn, D.P.J. Prescribing of antipsychotics in UK primary care: A cohort study. BMJ Open 2014, 4, e006135. [CrossRef]

66. Guthrie, B.; Makubate, B.; Hernandez-Santiago, V.; Dreischulte, T. The rising tide of polypharmacy and drug-drug interactions: Population database analysis 1995-2010. BMC Med. 2015, 13, 74. [CrossRef]

67. Welsh Government. Chief Medical Officer for Wales Annual Report 2015-2016. 2016. Available online: https://www.childreninwales.org.uk/policy-document/chief-medical-officer-wales-annual-report-20152016-111116-w/ (accessed on 25 September 2020).

68. Ryan, A.M.; Krinsky, S.; Kontopantelis, E.; Doran, T. Long-term evidence for the effect of pay-for-performance in primary care on mortality in the UK: A population study. Lancet 2016, 388, 268-274. [CrossRef]

69. Department of Health. Meeting the Challenge: A Strategy for the Allied Health Professions. 2000. Available online: http://www.nursingleadership.org.uk/publications/meetingthechallenge.pdf (accessed on 25 September 2020).

70. Drennan, V.M.; Grant, R.L.; Harris, R. Trends over time in prescribing by English primary care nurses: A secondary analysis of a national prescription database. BMC Health Serv. Res. 2014, 14, 54. [CrossRef]

71. Lesho, E.P.; Myers, C.P.; Ott, M.; Winslow, C.; Brown, J.E. Do clinical practice guidelines improve processes or outcomes in primary care? Mil. Med. 2005, 170, 243-246. [CrossRef] [PubMed]

72. Braithwaite, J.; Glasziou, P.; Westbrook, J. The three numbers you need to know about healthcare: The 60-30-10 Challenge. BMC Med. 2020, 18, 102. [CrossRef]

Publisher's Note: MDPI stays neutral with regard to jurisdictional claims in published maps and institutional affiliations.

(C) 2020 by the authors. Licensee MDPI, Basel, Switzerland. This article is an open access article distributed under the terms and conditions of the Creative Commons Attribution (CC BY) license (http://creativecommons.org/licenses/by/4.0/). 